IZA DP No. 10387

Free Primary Education, Schooling, and Fertility: Evidence from Ethiopia

Luke E. Chicoine

November 2016 


\title{
Free Primary Education, Schooling, and Fertility: Evidence from Ethiopia
}

\author{
Luke E. Chicoine \\ DePaul University \\ and IZA
}

\section{Discussion Paper No. 10387 \\ November 2016}

\author{
IZA \\ P.O. Box 7240 \\ 53072 Bonn \\ Germany \\ Phone: +49-228-3894-0 \\ Fax: +49-228-3894-180 \\ E-mail: iza@iza.org
}

Any opinions expressed here are those of the author(s) and not those of IZA. Research published in this series may include views on policy, but the institute itself takes no institutional policy positions. The IZA research network is committed to the IZA Guiding Principles of Research Integrity.

The Institute for the Study of Labor (IZA) in Bonn is a local and virtual international research center and a place of communication between science, politics and business. IZA is an independent nonprofit organization supported by Deutsche Post Foundation. The center is associated with the University of Bonn and offers a stimulating research environment through its international network, workshops and conferences, data service, project support, research visits and doctoral program. IZA engages in (i) original and internationally competitive research in all fields of labor economics, (ii) development of policy concepts, and (iii) dissemination of research results and concepts to the interested public.

IZA Discussion Papers often represent preliminary work and are circulated to encourage discussion. Citation of such a paper should account for its provisional character. A revised version may be available directly from the author. 


\section{ABSTRACT \\ Free Primary Education, Schooling, and Fertility: Evidence from Ethiopia}

This paper investigates the causal relationship between women's education and fertility by exploiting variation generated by the removal of school fees in Ethiopia. The increase in schooling caused by this reform is identified using both geographic variation in the intensity of the reform's impact and the temporal variation generated by the implementation of the reform. The model finds that the removal of school fees in Ethiopia led to an increase of over 1.5 years of schooling for women affected by the reform. A two-stage least squares approach is used to measure the impact of the exogenous increase in schooling on fertility. Each additional year of schooling led to a reduction in fertility, a delay in sexual activity, marriage, and the timing of at least their first, second, and third births. There is also evidence that the increase in schooling led to improved labor market outcomes, and a reduction in the desired number of children. Additionally, there is evidence of strategic use of hidden forms of contraception, only after family size becomes sufficiently large or after two sons have been born.

JEL Classification: $\quad$ O55, J13, I25, I26

Keywords: free primary education, Ethiopia, schooling, fertility

Corresponding author:

Luke Chicoine

Department of Economics

DePaul University

1 East Jackson Blvd, Suite 6200

Chicago, IL 60604

USA

E-mail: Ichicoin@depaul.edu 


\section{Introduction}

As evidenced by its prominent position among the Millennium Development goals, universal primary education has been a central goal of the international development effort for a number of years. As far back as the 1970s, the most readily available policy tool to promote enrollment has been the removal of schooling fees. This type of policy was implemented in Kenya and Nigeria in the 1970s, in Zimbabwe and Tanzania in the 1980s, in Ethiopia, Malawi, and Uganda in the 1990s, and has been aggressively pursued as a key tool in achieving the goal of universal primary education by international development organizations, as evidenced by over a dozen more countries removing schooling fees since the turn of the millennium (World Bank, 2009; Kattan and Burnett, 2004). Data from the UNESCO Institute for Statistics (UIS) show that, on average, these reforms increase enrollment by about 25 percent in the following year, but also increase pupil-teacher ratios by 10 percent. Work by Pritchett (2001) has called into question the efficacy of increases in schooling in developing parts of the world; the potential reduction in quality generated by these "big-bang" education reforms is a prime example of an environment in which a deterioration of the quality of schooling could fail to increase learning and improve the lives of the newly enrolled students. However, evidence of the returns to reductions in these user fees is lacking, as highlighted by the recent systematic education review from the International Initiative for Impact Evaluation (3ie - Snilstveit et al., 2016).

This paper evaluates the returns to a nationwide free primary education program in Ethiopia by examining the relationship between the additional schooling, generated by the removal of fees in grades one through ten, and women's fertility decision, as well as the potential mechanisms driving this relationship. In light of recent findings by Fort et al. (2016), that increases in education generated by 20th century compulsory schooling laws did not reduce fertility rates in continental Europe, the ex-ante expectation of a universally negative relationship between schooling and fertility has been called into question. However, using a twostage least squares (2SLS) model to identify the causal relationship, each additional year of schooling in Ethiopia is found to lead to a reduction of 0.164 births. The increase in schooling is identified by combining two dimensions of variation, the timing of the reform and geographic variation in education outcomes for cohorts who completed their schooling prior to the reform. The identification strategy employed in this paper uses age, schooling, and location data that are readily available for countries in most parts of the world. Motivated directly by the work from Bleakley (2010), Lucas (2010, 2013), and Lucas and Mbiti (2012a,b), the identification utilizes the concept that although the policy itself is applied uniformly across the country, the intensity of the reform in a specific location depends on the pre-existing characteristics of that area. In this setting, removing school fees from an area of high educational attainment will have a small impact relative to removing the same fees in an area with low pre-reform educational attainment. 
Investigating the mechanisms underlying the ways in which schooling impacts fertility decisions yields an increasing understanding of how and why women choose to change their behavior. This analysis finds that women's reduction in fertility is associated with a postponement in first birth through a delay in sexual activity in their late teens and reduced rates of marriage from the ages of 20 to 21 . As the impact on first birth dissipates, there is evidence that women delay their second and third births through the age of 24 .

The additional schooling generated by the removal of school fees is also found to lead to an increased likelihood of working, receiving cash payment for their work, and being less likely to work in subsistence farming and in agriculture more generally. The increase in labor market productivity found in these results likely led to an increase in the opportunity cost of raising children. In fact, the model finds evidence of a reduced demand for children.

Finally, although there is no evidence of an average increase in contraception use for the full sample, there is evidence that the increase in schooling led to a specific and strategic use of contraception. As family size grows, the increase in schooling leads to larger increases in contraception use, specifically with the use of contraception not visible to husbands. In addition to the evidence that women continue to delay the birth of their second and third child through the age of 24 , this evidence suggests escalating changes in behavior aimed at preventing future pregnancies, making it unlikely that births were simply delayed to later ages. The increased use of hidden contraceptives is also found in Zambia by Ashraf et al. (2014), but is associated with increased stress within the woman's relationship with her husband. This is likely due to the short experimental time frame within which women needed to make their decision. The increased use of hidden contraception in Ethiopia begins only after the second child is born, and for families with fewer than four children, only occurs if the family has two or more boys. These results suggest a specific and strategic behavior exhibited by women, who likely understand the preference for children that exists within their household, and may allow them to avoid the negative externality of contraception use found in Ashraf et al. (2014).

Earlier literature (Ainsworth et al., 1996; Lam and Duryea, 1999; Schultz, 1994, 1997) has documented the negative relationship in the data that exists between schooling and fertility. To identify the effect of education, McCrary and Royer (2011) exploit discontinuities at school-starting ages in California and Texas, Osili and Long (2008) use school construction in Nigeria, and Keats (2014) uses a discontinuity around the implementation of free primary schooling in Uganda. All three of these papers find that education led to a reduction in fertility, and the two papers examining schooling reforms in Africa find evidence of a reduction between 0.2 to 0.3 births for each additional year of school, similar to the effect size found in this paper. However, a number of other papers in the recent literature find evidence of an initial delay in fertility, but no change in total fertility (Black et al., 2008; Monstad et al., 2008; Fort, 2012; Geruso et al., 2014), and the 
previously mentioned paper by Fort et al. (2016) finds a positive causal relationship between schooling and fertility in continental Europe and a negative relationship in the UK. This literature finds surprisingly mixed results, suggesting the need for a greater understanding of the linkages between schooling and fertility.

The results found in this paper are significant in three ways. First, the paper presents an application of an identification strategy that can be applied to a number of settings to study national level reforms with a minimal amount of variables needed for identification. Measuring the impact of national level removal of user fees was one of the key categories found to need further study in the 3ie systematic review of education policy (Snilstveit et al., 2016). Second, the paper finds strong evidence of a negative relationship between schooling and fertility, and presents evidence of the pathways through which this relationship exists. Third, the paper finds significant evidence of positive returns to schooling, through both the reduction in fertility and improvement in labor market outcomes. This suggests that in the ways that matter most in developing parts of the world, the increased schooling generated by the reform, even in the presence of increasingly crowded classrooms, led to increases in education that bettered women's day-to-day life.

The paper proceeds as follows. The reform is described in greater detail in Section 2, and the strategy to identify the increase in schooling is outlined in Section 3. The empirical model is discussed in Section 4. Section 5 details the data used in the analysis, as well as the summary statistics of the sample. The results are discussed in Section 6, and Section 7 concludes.

\section{Background and Education Reform}

After 17 years of military and communist rule in Ethiopia, a transitional government took control in 1991. During the process of decentralizing power, this government made significant changes to the country's education policy (Ofcansky and Berry, 1993). The first of two pieces of legislation that impacted education policy was Proclamation No. 41, released in 1993. This law delegated the local provision of primary and secondary education to each of nine newly formed regional authorities and two independent administrations located in the country's largest cities (Negash, 1996; UNESCO, 2007; Tewfik, 2010). ${ }^{1}$ The second, the government's official Education and Training Policy (ETP) was published the following year, 1994, and officially forwarded to the regional governments prior to the 1995 school year. The release of the transitional government's official education policy, the ETP, was largely known at the time of Proclamation No. 41. This general knowledge, and the proclamation's decentralization of power, led to the functional implementation of the ETP at different times in different parts of the country between 1993 and 1996 (Negash, 1996; Oumer,

\footnotetext{
${ }^{1}$ The decentralization process led to an increase in teaching using local languages. Zenebe Gebre (2014) finds that the introduction of mother tongue education had a negative impact on enrollment and years of schooling. These findings suggest a downward pressure on schooling that would make finding a positive impact of the removal of school fees more difficult.
} 
2009; World Bank, 2009; UNESCO, 2007). This variation will be part of what is taken into account in the paper's empirical strategy.

The central consequence of the ETP was that it required that public education be fee-free for grades one through ten. The identification strategy used in this paper focuses on the removal of these fees, and the idea that the fraction of students completing these grades during the pre-reform period is likely inversely related to the magnitude of the reform's eventual impact. The ETP did not change the school starting age, which stayed consistent at seven years old, but did extend primary school from six to eight years, and set junior and senior secondary school to each be two years (Oumer, 2009; World Bank, 2009).

These reforms, both Proclamation No. 41 and the ETP, led to significant increases in enrollment in Ethiopia. Evidence of this increase can be seen using grade one enrollment data from UIS. As seen in Figure 1, there was a decline in enrollment in the late 1980's that coincides with the conflict that led to the eventual overthrow of the ruling government, but no immediate reversal following the end of the conflict in 1991. ${ }^{2}$ The initial increase in enrollment began in 1993 following the implementation of Proclamation No. 41; grade one enrollment increased by 45 percent, over 280,000 students. The second largest year-to-year growth was in 1995 and coincided with the implementation of the ETP; grade one enrollment increased by 317,000 relative to the previous year, an increase of 28 percent. These reforms ultimately led to an average increase in schooling of more than one full year, at least a six percentage point increase in passing the grade eight exam, and a roughly ten percentage point increase in the literacy rate (Chicoine, 2016).

There are a number of common critiques of this type of "big-bang" reform. First and foremost, decrees restricting local school's ability to levy tuition fees are difficult to enforce, and likely are not fully implemented. This type of a compliance problem only makes finding estimates more difficult. To the extent that fees are removed, this can cause a significant shortfall in the finances of local schools for which the central authorities are often not able to fully compensate. Although there were significant capital investments in Ethiopia that accompanied the reforms (World Bank, 2005), pupil-teacher ratios increased by 40 percent between 1992 and 1995, and by 60 percent if the time frame is extended to 1996. Growth in the number of students per school grew at an even faster rate, by 75 percent between 1992 and 1995 and 90 percent through 1996 (Ministry of Education, 1995, 1996, 2000). Although there has been some evidence of learning that coincided with the increase in enrollments, as discussed above, these types of difficulties following the rapid expansion of schooling are not unique to the Ethiopian experience (World Bank, 2009).

\footnotetext{
${ }^{2}$ Ethiopia uses their own calendar that begins its new year, and academic year, around the second week of the Gregorian (Western) September; the numerical Ethiopian year is either seven or eight years behind the Gregorian calendar depending on the time of year. The year referenced in the text is the Gregorian year in which the academic year began.
} 


\section{Identification Strategy}

The intensity of the Ethiopian education reform is jointly determined by both location within Ethiopia, and the timing of the reform's implementation. Although the ETP removed school fees in grades one through ten throughout Ethiopia, the local magnitude of the reform's impact depends on pre-reform levels of education in each part the country. This concept is similar to the Bleakley (2010) and Lucas (2010,2013) strategy that utilizes pre-eradication levels of malaria to identify local variation in the impact of eradication programs; Lucas and Mbiti (2012a,b) more directly applied this concept to the post-2000 removal of school fees in Kenya. A similar identification strategy can be applied to Ethiopia. Following the reform, ten years of feefree schooling became available to every single student; however, prior to the reform some portion of these grades were already being completed. In areas of the country where a higher number of years of schooling were already being completed, the removal of school fees would have a smaller impact relative to parts of the country where very few students attended school in the pre-reform period. Across Ethiopia, this pre-reform level of schooling will be evaluated for each of 60 zones in the country. ${ }^{3}$

The maximum potential magnitude of the reform's impact, $\overline{M_{z}}$, is calculated for each zone of Ethiopia. Conceptually, $\overline{M_{z}}$ is the maximum number of additional years of schooling that the reform could generate in zone $z$; which is simply the number of free years newly available; this will be roughly calculated as ten minus the average pre-reform education level in the zone. To standardize this value relative to the length of pre-reform primary school, which was six years, the difference is then divided by six. ${ }^{4}$ This will allow for future comparisons to reforms in other settings, and a magnitude value of one to be consistently interpreted as the "removal of primary school fees." It is important to note that the maximum impact of the reform, $\overline{M_{z}}$, will only fully impact cohorts who were born late enough that no matter what age they entered grade one they were able to do so in the post-fee environment.

The year that an individual is born combines with this magnitude measure to determine the intensity of the reform's impact. The year an individual is born determines the set of possible starting ages at which she could enter grade one prior to the implementation of school fees; alternatively, the school entry decision is made in the pre-reform environment. During both the pre- and post-reform periods, the official school entry age is at age seven. The probabilities of entering school at age six, one year early, to age twelve, five years late, are estimated for each zone. The pre-reform entry probabilities are taken from the data. To calculate the post-reform probabilities, the relative probabilities across all ages are held constant, and the sum of the post-reform entry probabilities are set to equal one, assuming every child could potentially enter school in

\footnotetext{
${ }^{3} \mathrm{~A}$ zone is the second administrative level, similar to counties in the United States.

${ }^{4}$ The calculation of the maximum magnitude of the reform: $\overline{M_{z}}=\frac{1}{6}\left(10-A v g_{z}\right)$. Where $A v g_{z}$ is the average pre-reform level of schooling in zone $z$.
} 
the fee-free environment. If a child is born in 1989 or later, even with a positive probability of starting school a year early, at age six, she would only face schooling decisions in the post-reform, fee-free, time period, and be assigned a zone specific reform intensity of $\overline{M_{z}}$. Children born in 1988 will face a pre-reform probability of starting school at age six; the fraction of students that enter at this age will not have the benefit of the reform in grade one, but only in grades two through ten. The remainder of the 1988 cohort, entering school at ages seven to twelve, will make their entry decision in the post-reform period and receive all ten years of benefit. Then for the 1987 cohort, entry at both ages six and seven are pre-reform. Age-six entrants start school two years prior to the reform and will only see the benefit from grades three to ten, and age seven entrants will only begin to receive the benefit when making the decision to continue grade two. The fraction of the cohort that did not enter at six and seven could then enter between eight and twelve, and would receive the full benefit across all ten years. This continues to iterate back to the 1973 cohort where children who enter school as late as possible in the calculation, at age twelve, would have only completed nine years of school in the pre-reform period, and would then have the opportunity to continue to a fee-free grade ten in the post-reform environment. Students born in 1972 are the first cohort not to be affected by the reform.

The intensity of the reform varies between the 1972 cohort, the final pre-reform cohort, to the 1989 cohort, the first fully post-reform cohort.

$$
I_{z y}= \begin{cases}0 & \text { if } y \leq 1972 \\ 0<M_{z y}<\overline{M_{z}} & \text { if } 1973 \leq y \leq 1988 \\ \overline{M_{z}} & \text { if } y \geq 1989\end{cases}
$$

The intensity of the reform, $I_{z y}$, is determined for zone $(z)$ and birth year $(y)$, and ranges between 0 and $\overline{M_{z}}$. An individual's location determines the magnitude of the reform's impact through both the zone's prereform level of schooling and school entry age probabilities, as discussed in the above paragraph. ${ }^{5}$ Location is matched using today's place of residence; in the dataset utilized in this paper information on place of birth is not available. However, data from 2014 Ethiopian Living Standard and Measurement Survey (LSMS) find that over 80 percent of adult respondents still live in their region of birth, suggesting that migration is not overly prevalent. Furthermore, Chicoine (2016) shows that analysis of the reform's impact on years of schooling using the LSMS data yield estimates similar to those using the DHS data from this paper, and that the estimates are not sensitive to three separate strategies to take into account the available migration data in the LSMS dataset. This is further evidence that the distinction between today's zone of residence

\footnotetext{
${ }^{5}$ The explicit equations used to calculate the full set of intensity measures $\left(I_{z y}\right)$ are discussed in detail in the appendix of Chicoine (2016).
} 
and place of birth is unlikely to significantly impact the results.

The final piece of the intensity calculation is to identify the timing of the reform in each region of Ethiopia; this must be done because a significant aspect of the reform was the decentralization of the provision of education (Negash, 1996; Oumer, 2009; UNESCO, 2007; World Bank, 2009). Pre-reform (1989 to 1992) grade one enrollment data from the Ministry of Education $(1995,1996,2000)$ are available at the regional level for each of the country's eleven regions, and used to predict enrollment over the next four years (1993 to 1996). The annual grade one enrollment level is then compared to the predicted level in each region for the years between 1993 and 1996. Each region is set to be fully implemented at the year furthest above the trend, and the fraction below that level in the previous years sets the level of partial implementation. ${ }^{6}$ The practical implication of this on the intensity measure is to simply shift the 1972 and 1989 birth cohort cutoffs two years earlier (i.e. 1970 to 1987) for regions that implemented the reform with the 1993 release of Proclamation No. 41, and to one year later for the regions that were slowest to implement the reform (i.e. 1973 to 1990). The main analysis of this paper includes birth cohorts from 1970, the first fully pre-reform cohort, to 1990, the first fully post-reform cohort. This is the narrowest band of birth cohorts possible that fully captures the impact of the reform. ${ }^{7}$

\section{Estimation Strategy}

The central estimating model is a 2SLS model. The first-stage is defined by the following equation:

$$
\operatorname{YrsSchl}_{i z y}=\theta_{0}+\theta_{1} I_{z y}+\sum_{p=1}^{3} \theta_{2}^{p} a g e_{i z y}^{p}+\delta_{z}+\tau_{y}+\delta_{z} \operatorname{Trend}_{y}+\nu_{i z y}
$$

The dependent variable is $\operatorname{YrsSch}_{i z y}$, the years of schooling for person $i$, from zone $z$, and born in year $y$, and $I_{z y}$ is the zone and birth year specific estimated intensity of the reform described in Section 3 . The value of $I_{z y}$ is scaled to equal one when six years of school, the pre-reform length of primary school, are provided fee-free; therefore, first stage estimates of $\theta_{1}$ can be interpreted as the impact of providing free primary education. A third order polynomial in age is included to take into account that two waves of the DHS survey are used, and $\tau_{y}$ is a set of birth year-specific fixed effects that capture any cohort-specific effects of the reform. $\delta_{z}$ is a vector of zone-specific fixed effects that capture any time invariant characteristics of the different areas throughout Ethiopia, and $\delta_{z} \operatorname{Trend}_{y}$ is a set of zone-specific linear trends that captures

\footnotetext{
${ }^{6}$ Estimates removing the partial implementation are also shown in Table 3, Table 4, and Appendix Table A4. Across the regions the reform is set to be fully implemented in the following years: Tigray 1993, Afar 1993, Amhara 1995, Oromiya 1995, Somalia 1993, Benishangul Gumuz 1993, Southern Nations, Nationalities, and Peoples' Region 1995, Gambella 1993, Harari 1995, Addis Ababa 1995 and Dire Dawa 1996.

${ }^{7}$ Estimates using alternative cohort samples are shown in Table 3, Table 4, and in Appendix Table A3.
} 
secular changes over time, within each zone of Ethiopia. ${ }^{8}$ This first-stage equation is then used to estimate the exogenous increase in schooling generated by the removal of school fees in Ethiopia. The predicted increase in schooling can then be used in the second stage to estimate the causal relationship between schooling and births, or any other outcome of interest.

$$
B_{i z y}=\alpha_{0}+\beta_{1} Y \widehat{r s S}{ } h l_{i z y}+\sum_{p=1}^{3} \alpha_{2}^{p} a g e_{i z y}^{p}+\phi_{z}+\mu_{y}+\phi_{z} \operatorname{Trend}_{y}+\varepsilon_{i z y}
$$

The dependent variable $B_{i z y}$ is the outcome of interest, initially number of births, for person $i$, from zone $z$, and born in year $y$. The second-stage equation uses the same set of control variables as equation (2), and the coefficient on the predicted years of schooling, $\beta_{1}$, captures the causal impact of one additional year of schooling exogenously generated by the education reform. Standard errors are clustered by zone to allow for within zone correlation (Bertrand et al., 2004).

The ordinary least squares relationship (OLS) between schooling and fertility can be studied using a modified version of equation (3), by replacing the predicted level of schooling with each individual's actual level of schooling, $\operatorname{YrsSch} l_{i z y}$. However, the OLS estimates are likely biased if schooling is correlated with unobservable characteristics that also affect the number of children women choose to have. If women who are more likely to obtain higher levels of schooling also have higher career ambition and lower levels of desired fertility, the OLS estimates would be biased. This suggests that the negative relationship that is expected to be found in the OLS relationship could be generated by an omitted variables bias; causal identification requires an alternative strategy, such as that proposed in this paper.

The central assumption underlying this identification strategy is that the removal of school fees in Ethiopia only impacts these woman's fertility decision through its effect on their level of schooling. This requires that their year of birth, and their location of schooling be orthogonal to their exposure to the reform. While the timing of birth provides little concern, the zone of residence and schooling would be the dimension more likely to trouble this assumption. This would be problematic if women and families relocated at the time of the reforms implementation in such a way that higher ability students sorted into areas with higher predicted intensity of the reform. However, this type of sorting is unlikely to occur in this setting. The intensity measure is explicitly designed to predict a greater impact of the reform in areas with lower initial levels of schooling. A violation of this assumption would require the unlikely scenario that higher ability families were moving to areas that were worse off at the time of implementation. Furthermore, as mentioned previously, Chicoine (2016) finds evidence that estimates adjusting for migration using three different techniques yield

\footnotetext{
${ }^{8}$ The set of fixed effects and trends is similar to the empirical strategy used by a number of previous studies evaluating education reforms. These studies include Black et al. (2005), Bleakley (2010), Lucas and Mbiti (2012a,b), Fort et al. (2016), Holmlund et al. (2011), and Lundborg et al. (2014).
} 
results similar to the baseline estimates, and also finds no evidence of a similar effect on education in settings where no reform occurred (Kenya, Tanzania, Zambia, and Mali).

An alternative concern could be that the relative geographic distribution of the quality of schooling changed at the time of the reform. For example, if the reform led to the government increasing resources to the parts of the country that had lower pre-reform levels of schooling the effect estimated by $\beta_{1}$ would include returns to this type of investment. This would still be the estimated effect of the reform, but not explicitly the effect of the removal of school fees. Examining the correlation between pre-reform education levels and the change in regional spending on education provides insight into how funding was allocated following the implementation of the reform; finding a strong negative correlation would suggest a disproportion increase in funding to areas with lower pre-reform levels of education, and would be problematic. However, regional per student spending data in 1993, the first year data are available, exhibits a strong positive correlation with pre-reform education levels. Then looking at the change in spending relative to 1996, as the reform is implemented, and in 2001, well after the implementation, yields correlations of 0.01 and 0.17 , respectively (World Bank, 2005). This suggests very little relationship between pre-reform education levels and the investment decisions of the regional governments. It is more likely that the reform actually led to reduction in school quality. In addition to the negative impact of mother tongue education found by Zenebe Gebre (2014), the number of students per teacher increased over 50 percent in the years following implementation of the reform. This likely deterioration of quality, which accompanies many of these large reforms, would put downward pressure on the estimates of schooling, making identification more difficult.

\section{Data}

The geographic variation used in the construction of the paper's intensity measure is calculated using data from the 1994 Ethiopian Census. These data were collected by the Ethiopian Central Statistical Agency, and made available as part of the Integrated Public Use Microdata Series (IPUMS) International by the Minnesota Population Center (2015). A sample of over 180,000 women born between 1966 and 1969 is constructed to estimate the pre-reform level of education in each of the zones across Ethiopia. Data from the census for girls age 6 to 12, a sample of over 500,000 observations, are also used to calculate zone specific school entry likelihoods for each age. Using birth year and region of residence information, the instrument calculated with these data is merged with individual outcome data to estimate the effect of the Ethiopian reform, and the eventual impact of the exogenous increase in schooling on fertility rates.

Individual level outcome data for Ethiopian women are from 2005 and 2011 rounds of the Ethiopian Demographic and Health Survey (DHS). The data used in this paper are from the merged individual women 
and birth history datasets. The individual women dataset includes detailed information regarding birth date, district of residence, education, health, contraceptive use, employment, household wealth, characteristics of their husbands, and age at first marriage, sexual intercourse and birth. The birth history data include retrospective information on the woman's age at the time of birth for each of her children. Not only do these data allow for the measurement of how an exogenous increase in schooling can impact the total number of births, it is also possible to identify the effect on the number of births at any given age.

The summary statistics of the DHS data used in paper are presented in Table 1. The table provides information for women in pre-reform cohorts, born between 1966 and 1970, and late- and post-reform cohorts, born between 1986 and 1990. Age 24 means are also include the 1985 cohort to include two cohorts above the age of 24 in the calculation. Although later cohorts are younger, they have a higher level of education and far fewer births. For this reason it can be informative to examine the number of births at each age, ages 15,17 , 20, 22 and 24 are shown in the table for six key variables. These samples only include women older than the stated age, and allow for an apples-to-apples comparison, for example, for the number of births by age 20 . For all six of these measures, a consistent pattern emerges. Relative to the 1966 and 1970 cohorts, women in the later cohorts have fewer children at each age, and also postpone first sexual intercourse, marriage, and birth to later ages. The portions of these differences that can be explained by the increase in education generated by the reform is examined in the following section.

\section{Results}

\subsection{Ordinary Least Squares}

To begin the analysis, the OLS relationship documents the general correlation seen in the data. This is done by estimating equation (3) using the years of schooling data, not the predicted level from first stage. A negative relationship between fertility and schooling has been well documented in the literature (Ainsworth et al., 1996; Lam and Duryea, 1999; Schultz, 1994, 1997), and is also found in the data from Ethiopia. The OLS estimates are shown in Table 2. The estimate in column (1) is for total number of all births for women 15 years of age and above, the model estimates a negative and statistically significant relationship between schooling and fertility.

Additionally, it could be interesting to examine how schooling impacts fertility rates across different ages, and although a cubic in age is included in the model, estimating the relationship between schooling and fertility at specific ages has the added benefit of comparing women at a fixed point in their lives. The estimates in columns (2) through (11) use the total number of births by the stated age as the dependent 
variable, for a sample of women who were at least one year older at the time of the survey. Across all ten estimates, the OLS model again finds a negative and statistically significant relationship between years of schooling and fertility. However, as discussed previously these estimates are unlikely to describe a causal relationship between schooling and fertility if unobserved characteristics that impact a woman's schooling also affect her fertility decision. To address this concern, an exogenous increase in schooling generated by the education reform in Ethiopia is identified, and an instrumental variables technique is used to examine the impact of this increase in education on women's fertility.

\subsection{First-Stage Estimates: Effect of Reform on Years of Schooling}

Before linking schooling to fertility, it is important to examine whether exposure to the education reform in Ethiopia did generate an identifiable increase in years of schooling. The impact of the education reform is estimated by regressing years of schooling on the zone and birth year specific intensity measure described in Section 3; the first-stage estimating equation is described by equation (2). The results from five different specifications are shown in Table (3).

All estimates in Table (3) include a cubic control for age, a set of zone fixed effects, a set of birth year fixed effects. Estimates in column (4) use region- (i.e. province) specific trends, while the estimates in the other four columns use more localized zone-specific time trends. The model in column (1) allows for an incremental implementation of the education reform, as described at the end of Section 3, and the sample includes all women born between 1970 and 1990. This is the preferred intensity measure and sample for the paper. The first-stage estimate described in column (1) finds that the reform led to an increase in schooling of just over 1.7 years of school, the F-statistic is 21.32. The largest change in the estimated coefficient on schooling is in column (2) when the reform is forced to be implemented uniformly within each region; however, the model still finds an increase of over 1.25 years of schooling, and F-statistic of 14.55. Column (3) uses the baseline sample with region-specific trends, columns (4) to (7) estimate the model using alternative samples. The full set of estimates consistently find strong evidence that the education reform in Ethiopia led to an average increase of over one additional year of schooling for Ethiopian women.

\subsection{SLS: Effect of Years of Schooling on Fertility}

The results from the first-stage demonstrate the strength in the instrument's ability to identify the increase in schooling generated by the removal of school fees in Ethiopia. Estimating the second stage of the 2SLS model focuses on the relationship between the predicted level of education and birth rates, as described in equation (3). The results in Table 4 use the same seven variations of the model used to estimate the 
first-stage, and all seven estimates find a statistically significant and negative relationship between schooling and women's lifetime number of births. Furthermore, all seven specifications yield similar point estimates; each additional year of schooling leads to between 0.16 and 0.2 fewer births. This estimates about 50 percent larger than the corresponding OLS estimate in Table $2 .{ }^{9}$

In addition to looking at the relationship between schooling and total number of births, the number of births at specific ages, from 15 to 24 , are again examined in Table $5 .{ }^{10}$ At the younger ages, 15 and 16 , there is no effect of schooling on births. Not only is the pre-reform average number of births at these ages relatively low, about 0.23 , but the average years of schooling in the pre-reform sample is only 2.35 , which combined with the small estimates at these younger ages, makes it unlikely that any type of incarceration effect, women physically being in the classroom, is affecting the results in the paper (Black et al., 2008). Beginning at age 17, the point estimate becomes increasingly negative, and statistically significant at the 90 percent level at age 18. Each additional year of schooling reduces the number of births a woman has by the age of 18 by 0.088 births, nearly 12 percent off of the pre-reform average of 0.74 . At the age of 20 , the magnitude of the point estimate again increases, becoming increasingly negative, and takes another jump of an additional reduction in fertility of about one-tenth of a birth at the age of 22 . At the last two ages that can be examined, the effect continues its downward trend, becoming increasingly negative while becoming statistically significant at the 99 percent confidence level. Although women are likely to have more children beyond the age of 24 , the negative trend is the first piece of evidence that suggests it is likely that the effect becomes increasingly negative at later ages. Furthermore, the effect at the age of 24 is already more negative than the results seen in Table 4, when younger women are included in the sample. As seen in Table 5, the increase in schooling does not significantly impact the fertility rate for these younger women, suggesting that the effect of schooling for women older than 24 would have to remain increasingly negative to balance out their zero result. This evidence, as well as later evidence that finds an increased likelihood of contraception use, suggests an effect of the increase in schooling that persists through later ages.

The effect of an additional year of schooling on the timing of a woman's first birth (dashed bars), second birth (white), and third birth (black) is shown in Figure 2. The three ages at which the effect of schooling on the number of births exhibits a large jump in Table 5 are 17, 20 and 22. All three of these increases are associated with delays in the timing of each subsequent birth. Beginning at the age of 17 , the increase in schooling led to a large and statistically significant reduction in the likelihood of a woman having her first child. Each additional year of school reduced the likelihood of having a child at the age of 17 by nearly 7.9 percentage points; a reduction of 21 percent of the pre-reform average. This large increase in the reduced

\footnotetext{
${ }^{9}$ The magnitude of both the OLS estimates and the 2SLS estimates are similar to those from Osili and Long (2008) in Nigeria, Keats (2014) in Uganda, and Fort et al. (2016) in the United Kingdom.

${ }^{10}$ The first-stage F-statistic is not strong enough to take meaningful inference away from the results beyond 24 .
} 
likelihood of first birth coincides with the first large decrease in overall number of births seen in Table 5 . The next large decline in Table 5 is at the age of 20 . This is the same age at which the increase in schooling begins to reduce the likelihood of a woman having her second birth. The final significant increase in the effect of schooling on the number of births is at the age of 22 , exactly the same age at which women begin delaying their third birth. ${ }^{11}$ Some portion of this effect is likely due to residual delays from the first and second birth; however, the reduced likelihood of third birth does not significantly decline over the next two ages and remains larger than the effect on earlier births. This evidence suggests that the timing of the increasingly large reductions in fertility found in Table 5 are associated with the ages at which the increase in schooling begins to impact the likelihood of each additional birth. This is an encouraging sign that the estimates are identifying a meaningful decline in birth rates.

Figure 3 provides an interesting insight into behavioral changes associated with the timing of a woman's first birth. For comparison, the first birth information is the same as Figure 2, and the scale on the vertical axis is held constant. The white bars denote the effect of an additional year of schooling on the likelihood of first sexual intercourse by each given age; the effect on age of first marriage is shown with the black bars. For each additional year of schooling, the model estimates a reduction in the likelihood of having sex by age 16 of 6 percentage points. This change in behavior would begin to impact a woman's likelihood of first birth nine months later. At age 17, for the first time, there is a large and statistically significant decline in the likelihood of a woman having her first child of 7.9 percentage points. The reduction in sexual activity continues for the next two ages, 17 and 18, before beginning to dissipate as women age into their 20s. At the ages of 18 and 19 there were again statistically significant reductions in first birth. At the ages of 20 and 21, each additional year of schooling reduces the likelihood of marriage by 6.4 and 5.3 percentage points, respectively. These are ages that are not preceded by a decline in first sexual intercourse, but still have large reductions in first birth of a magnitude similar to the effect on marriage. ${ }^{12}$ The results outlined in Figure 3 suggest that the increase in education in Ethiopia generated by the reform led to women postponing their first birth through the delay of sexual activity in their late teens, the postponement of marriage at the ages of 20 and 21. Furthermore, the evidence in Figure 2 suggests that birth rates declined through women's delay of each successive birth.

\footnotetext{
${ }^{11}$ The t-statistic on the third birth coefficient at age 22 is 1.59 .

${ }^{12}$ The timing between marriage and first birth does not need have the same biological delay as the relationship between sexual activity and first birth. Of the married women in the sample, 16.09 percent had their first child prior to nine months after marriage.
} 


\subsection{Additional Mechanisms}

The results in the previous section find that the increase in education in Ethiopia generated by the reform led to a reduction in fertility, and described the behavior through which this reduction occurred. However, this does not explain why these women decided to change their behavior. There are two broad, but not mutually exclusive, possibilities that could explain why education led to a reduction in fertility rates. The general economic theory for why there could be a negative relationship between schooling and fertility rates is that increases in schooling should increase worker productivity. If this occurs, the reform would not merely be generating an increase in schooling, but an actual increase in education, in learning, that is allowing these women to become more productive. This increase in productivity would generate an increase in the cost of the women's time, and of their opportunity cost of raising children. An increase in opportunity cost would manifest itself in a reduced demand for children, and smaller ideal family size. A second channel through which the increase in education could lead to reduced fertility rates, is by increasing a woman's ability to make her own personal decisions. This could be generated through an increase in the level of labor market potential, standing relative to her husband, or by simply generating a better understanding of her opportunities and rights. Women generally desire fewer children than their husbands, and an increase in relative power in the decision-making process would likely lead to smaller family size. ${ }^{13}$ Alternatively, some combination of these two possibilities could occur.

The results in Table 6 begin to examine both of these possibilities. Specifically, results (1) through (6) examine the effect of schooling on women's labor market outcomes and their ideal family size. Result (1) finds that each additional year of schooling reduces a woman's ideal number of children by 0.277. The magnitude of this change is larger than the estimated reduction in number of births in Table 4, for the full sample, but similar to the reduction in number of births at the age of $24 .^{14}$ Although income data are not included in the DHS, the next five results show that each additional year of schooling led to statistically significant increases in the likelihood of working, earning cash payment for their work, not working in subsistence agriculture, not working in agriculture more broadly, and in household wealth. All of these measures yield evidence of an increase in productivity for women following the reform, and the expected result that the increase in the opportunity cost of their time is associated with a smaller ideal family size.

The final four results in Table 6 examine whether the increase in education led to an increase in woman's ability to make household decisions, and potentially impact her family size through a change in the household bargaining process. Result (7) finds evidence that each additional year of schooling increases the likelihood

\footnotetext{
${ }^{13}$ More than one-in-three pre-reform women report their husband wanting relatively more children, while only nine percent report that they would like to have a larger family than their husband.

${ }^{14}$ Importantly, there was no statistically significant effect on the non-numeric response of "up to god"; ten percent of prereform women gave this response.
} 
that a woman reports no justification for a husband beating his wife by 5.4 percentage points. ${ }^{15}$ Although this result suggests a possibly strengthened position in the household, there is no change in women's age (8) or education (9) relative to their husband, and there is no change in married women reporting that they have a say in their own health care decisions, large household purchases, or ability to visit relatives. ${ }^{16}$ Finally, result (10) shows the estimated effect of schooling on the health care decision that would most enable women to better control their fertility decision, their use of modern contraception, and finds no evidence of an effect.

However, further analysis of contraception use yields an interesting and important pattern. Ashraf et al. (2014) find that when women are able to privately make their decision regarding the use of contraception they use contraception not visible to their husband, and that it creates an increased level of stress in their relationship, a potential drawback. This complication is largely due to the short window in which the experiment operates, and the women are required to make their decision. If women have this type of a preference, it is possible that they understand their environment well enough to be able to take up contraception in a way that avoids the difficulty found in Ashraf et al. (2014).

The key take-away from the following results is the demonstrated pattern. As the sample is cut into smaller groups, the power in the first-stage is significantly reduced; therefore, reduced form estimates are examined. ${ }^{17}$ The interesting piece of initial evidence is outlined in Figure 4 . The gray bars show the effect of an additional year of schooling on hidden contraception, and the black bars, the effect on any type of modern contraception technology. ${ }^{18}$ The full sample result for any modern contraception is the same as the estimate in Table 6. Furthermore, there is no effect on the use of hidden contraception in the full sample, and the results for women with at least one child are also estimated zeros. However, when women have their second child, the point estimates of the effect of an additional year of schooling increase on both categories of contraceptives increase, and continue to do so through the estimates of families with four children or more. The positioning of this increase is not random. It will be shown that women significantly change their behavior regarding contraception use following the birth of their second son, which is obviously only possible after having at least two children. Furthermore, the effect on hidden forms of contraception consistently track the change in overall use of any method, suggesting that women are generally making this decision on their own.

The estimates in Table 7 are generated using samples defined by whether a woman has given birth to at least two boys. It is important to note that in Ethiopia, irrespective of a family's current sex mix of

\footnotetext{
${ }^{15}$ Estimating the model using a sample of married women yields a point estimate of a 7.6 percentage point reduction, and is statistically significant at the 90 percent confidence level.

${ }^{16}$ Point estimates can be found in Appendix Table A2.

${ }^{17}$ First stage estimates remain qualitatively similar for the following samples ranging from 0.595 to 2.953 , but F-statistics are no higher than 6.56 .

${ }^{18}$ Hidden contraception is defined as either IUD, injections, or implants; these are not visible, and do not need to be taken daily.
} 
children, boys are consistently 52 percent of births. The key take away from Table 7 , is that the estimates on the top half of the table, for samples with at least two boys, find a consistently large increase in the use of contraception. The estimates on the bottom of the table, for women with fewer than two boys, find relatively small and more often statistically insignificant estimates. However, the estimates in the bottom half of the table increase with family size. The results in columns (1) and (2) use the most broadly defined sample, ignoring birth order. When the woman has at least two sons, her use of modern (and hidden) contraception increases following the education reform. These results find consistent evidence that increased schooling does lead to higher rates of contraception use, as family size grows, and following the birth of their second son. Taken in conjunction with the Ashraf et al. (2014) findings, and the matching increases in hidden contraception use found in this paper, the evidence suggests that women are acting very strategically to avoid the negative intra-household difficulties associated with contraception use found in Ashraf et al. (2014). Before increasing their use of hidden contraception, women are letting their families become sufficiently large, or having what they seem to believe is an acceptable number of sons. The behavior seems to be targeted to very specific family sizes, and sex mixes, suggesting some type of optimization between desired family size and household tranquility.

\section{Conclusion}

This paper finds evidence that free primary education led to an increase in schooling in Ethiopia, and that the increase in schooling led to a significant reduction in number of births for Ethiopian women. This reduction was generated through a delay in sexual activity, marriage, and birth. Evidence of a reduced demand for children was also found to be associated with increased labor market returns. Finally, the higher level of schooling also led to an increase in the strategic use of contraception as family size grows, and when women have at least two sons. Following recent results in the literature that call into question the general understanding of a universally negative relationship between schooling and fertility, these findings become increasingly important. Beyond the top line result that fertility declined, these estimates also yield useful insight into the mechanisms through which schooling impacts fertility decisions.

The identification strategy used in this paper is able to causally identify the returns to increased levels of schooling using only pre-reform schooling and location information. This strategy allows for the identification of national level reforms by exploiting variation in pre-existing levels of education. This can be a powerful tool for examining the return to free primary education in any number of countries, an area of research highlighted by 3ie (Snilstveit et al., 2016) as an area in which more study is needed. Furthermore, this paper shows strong evidence of a positive return to schooling, even in the presence of large increases in pupil-teacher 
ratios. This result suggests that large increases in enrollments are able to outweigh the possible negative impact of declining education quality. This is important because the removal of school fees is a policy lever that has been successfully used in many parts of the world, and consistently generates strong enrollment responses. It will be of great benefit to policy makers to know if similar reforms generate the same type of positive returns to schooling. 


\section{References}

Ainsworth, M., Beegle, K., and Nyamete, A. (1996). The Impact of Women's Schooling on Fertility and Contraceptive Use: A Study of Fourteen sub-Saharan African Countries. World Bank Economic Review, 10(1):85-122.

Ashraf, N., Field, E., and Lee, J. (2014). Household Bargaining and Excess Fertility: An Experimental Study in Zambia. American Economic Review, 104(7):2210-2237.

Bertrand, M., Duflo, E., and Mullainathan, S. (2004). How Much Should We Trust Differences-In-Differences Estimates? Quarterly Journal of Economics, 119(1):249-275.

Black, S. E., Devereux, P. J., and Salvanes, K. G. (2005). Why the Apple Doesn't Fall Far: Understanding Intergenerational Transmission of Human Capital. American Economic Review, 95(1):437-449.

Black, S. E., Devereux, P. J., and Salvanes, K. G. (2008). Staying in the Classroom and Out of the Maternity Ward? The Effect of Compulsory Schooling Laws on Teenage Births. Economic Journal, 118(530):10251054 .

Bleakley, H. (2010). Malaria Eradication in the Americas: A Retrospective Analysis of Childhood Exposure. American Economic Journal: Applied Economics, 2(2):1-45.

Chicoine, L. (2016). Identifying National Level Education Reforms in Developing Settings: An Application to Ethiopia. IZA Discussion Paper No. 9916.

Fort, M. (2012). Empirical Evidence on the Role of Education in Shaping Female Fertility Patterns. Working Paper, University of Bologna.

Fort, M., Schneeweis, N., and Winter-Ebmer, R. (2016). Is Education Always Reducing Fertility? Evidence from Compulsory Schooling Reforms. Economic Journal, 126(595):1823-1855.

Geruso, M., Clark, D., and Royer, H. (2014). The Impact of Education on Family Formation: Quasiexperimental Evidence from the UK. Working Paper, University of California, Santa Barbara.

Holmlund, H., Lindahl, M., and Plug, E. (2011). The Causal Effect of Parents' Schooling on Children's Schooling: A Comparison of Estimation Methods. Journal of Economic Literature, 49(3):615-651.

Kattan, R. B. and Burnett, N. (2004). User Fees in Primary Education. World Bank Education Advisory Service. Washington D.C. World Bank. 
Keats, A. (2014). Women's Schooling, Fertility, and Child Health Outcomes: Evidence from Uganda's Free Primary Education Program. Working Paper, Wesleyan University.

Lam, D. and Duryea, S. (1999). Effects of Schooling on Fertility, Labor Supply, and Investments in Children, with Evidence from Brazil. Journal of Human Resources, 34(1):160-192.

Lucas, A. M. (2010). Malaria Eradication and Educational Attainment: Evidence from Paraguay and Sri Lanka. American Economic Journal: Applied Economics, 2(2):46.

Lucas, A. M. (2013). The Impact of Malaria Eradication on Fertility. Economic Development and Cultural Change, 61(3):607-631.

Lucas, A. M. and Mbiti, I. M. (2012a). Access, Sorting, and Achievement: the Short-Run Effects of Free Primary Education in Kenya. American Economic Journal: Applied Economics, 4(4):226-253.

Lucas, A. M. and Mbiti, I. M. (2012b). Does Free Primary Education Narrow Gender Differences in Schooling? Evidence from Kenya. Journal of African Economies, 21(5):691-722.

Lundborg, P., Nilsson, A., and Rooth, D.-O. (2014). Parental Education and Offspring Outcomes: Evidence from the Swedish Compulsory School Reform. American Economic Journal: Applied Economics, 6(1):253278.

McCrary, J. and Royer, H. (2011). The Effect of Female Education on Fertility and Infant Health: Evidence from School Entry Policies Using Exact Date of Birth. American Economic Review, 101(1):158-195.

Ministry of Education (1995). Education Statistics Annual Abstract 1986 EC (1993-94). Technical report, Ministry of Education (Ethiopia), Addis Ababa.

Ministry of Education (1996). Education Statistics Annual Abstract 1987 EC (1994-95). Technical report, Ministry of Education (Ethiopia), Addis Ababa.

Ministry of Education (2000). Education Statistics Annual Abstract 1992 EC (1999-00). Technical report, Ministry of Education (Ethiopia), Addis Ababa.

Minnesota Population Center (2015). International Public Use Microdata Series, International: Version 6.4. [Machine-readable database].

Monstad, K., Propper, C., and Salvanes, K. G. (2008). Education and Fertility: Evidence from a Natural Experiment. Scandinavian Journal of Economics, 110(4):827-852.

Negash, T. (1996). Rethinking Education in Ethiopia. Uppsala. Nordiska Afrikainstituet. 
Ofcansky, T. P. and Berry, L. B. (1993). Ethiopia, A Country Study. Washington DC. Federal Research Division, Library of Congress.

Osili, U. O. and Long, B. T. (2008). Does Female Schooling Reduce Fertility? Evidence from Nigeria. Journal of Development Economics, 87(1):57-75.

Oumer, J. (2009). The Challenges of Free Primary Education in Ethiopia. UNESCO: International Institute for Educational Planning.

Pritchett, L. (2001). Where Has All the Education Gone? World Bank Economic Review, 15(3):367-391.

Schultz, T. P. (1994). Human Capital, Family Planning, and Their Effects on Population Growth. American Economic Review, 84(2):255-260.

Schultz, T. P. (1997). Demand for Children in Low Income Countries. Handbook of Population and Family Economics, 1:349-430.

Snilstveit, B., Stevenson, J., Menon, R., Phillips, D., Gallagher, E., Geleen, M., Jobse, H., Schmidt, T., and Jimenez, E. (2016). The Impact of Education Programmes on Learning and School Participation in Low-and Middle-Income Countries. 3ie Systematic Review Summary, 7. London: International Initiative for Impact Evaluation (3ie).

Tewfik, H. (2010). Transition to Federalism: The Ethiopian Experience. Forum of Federations.

UNESCO (2007). World Data on Education. Geneva. UNESCO: International Bureau of Education.

World Bank (2005). Education in Ethiopia: Strengthening the Foundation for Sustainable Progress. Washington D.C. World Bank.

World Bank (2009). Abolishing School Fees in Africa: Lessons from Ethiopia, Ghana, Kenya, Malawi, and Mozambique. Washington D.C. World Bank.

Zenebe Gebre, T. (2014). Effects of Mother Tongue Education on Schooling and Child Labor Outcomes. Working Paper, University of Notre Dame. 


\section{Figures}

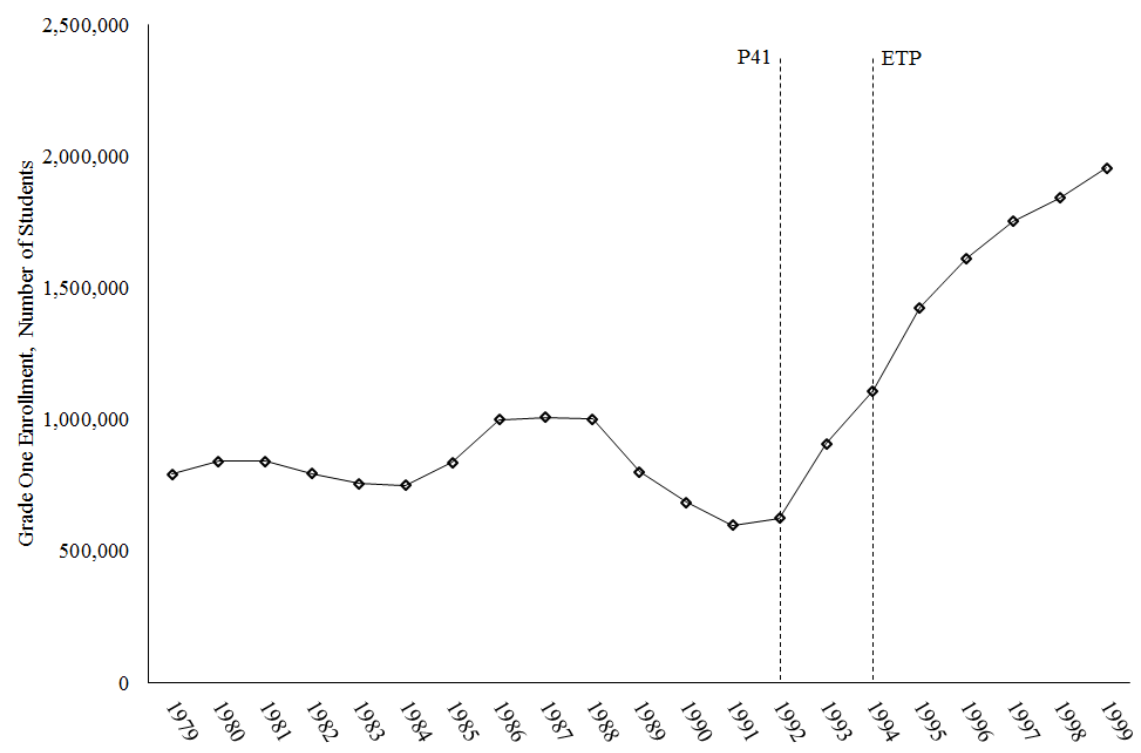

Figure 1: Grade One Enrollment, By Academic Year

Note: P41 refers to Proclamation No. 41, and ETP to the Education and Training Policy. Source: UNESCO Institute for Statistics.

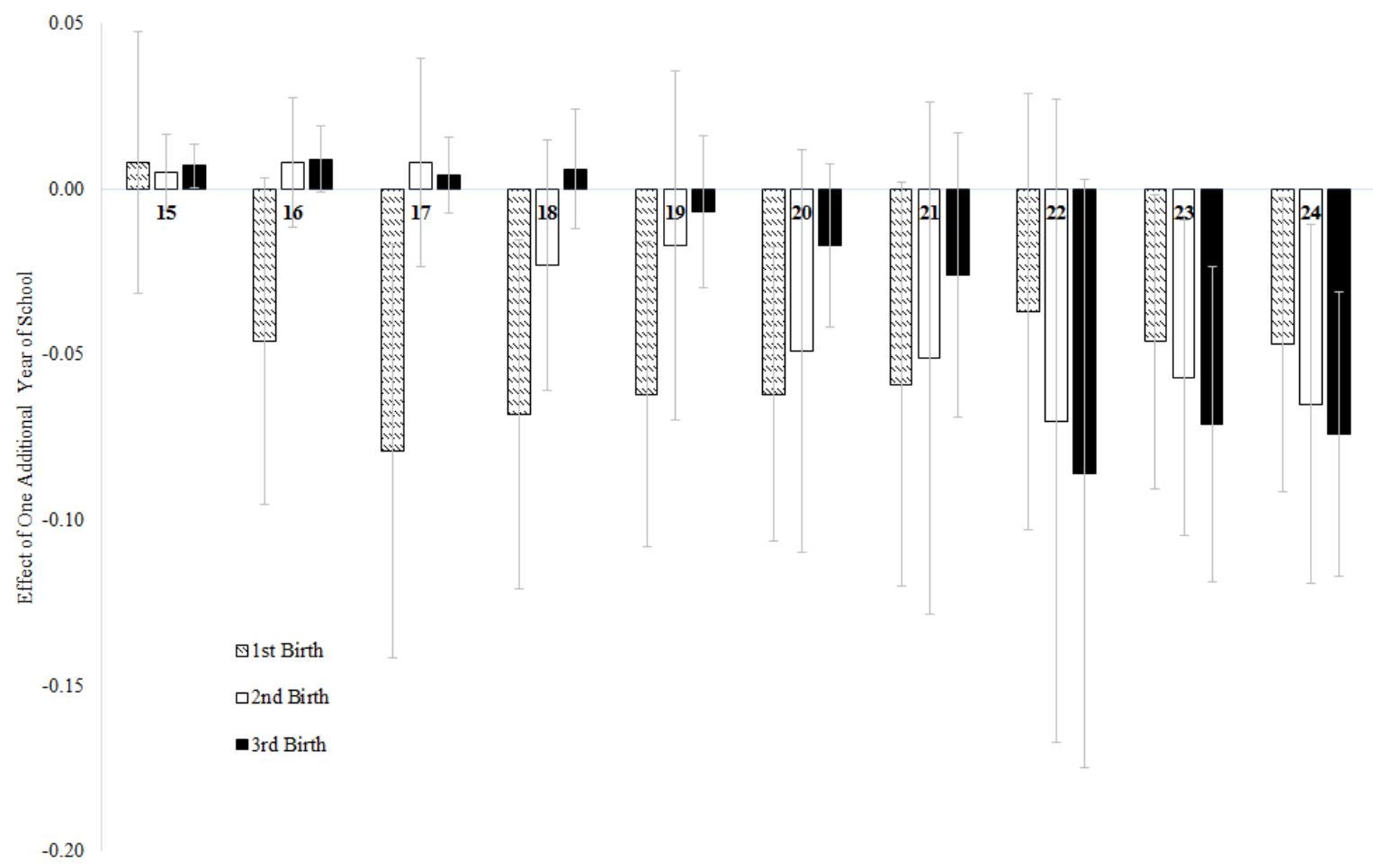

Figure 2: Effect of Years of Schooling on Age at First, Second, and Third Birth (90\% C.I) 


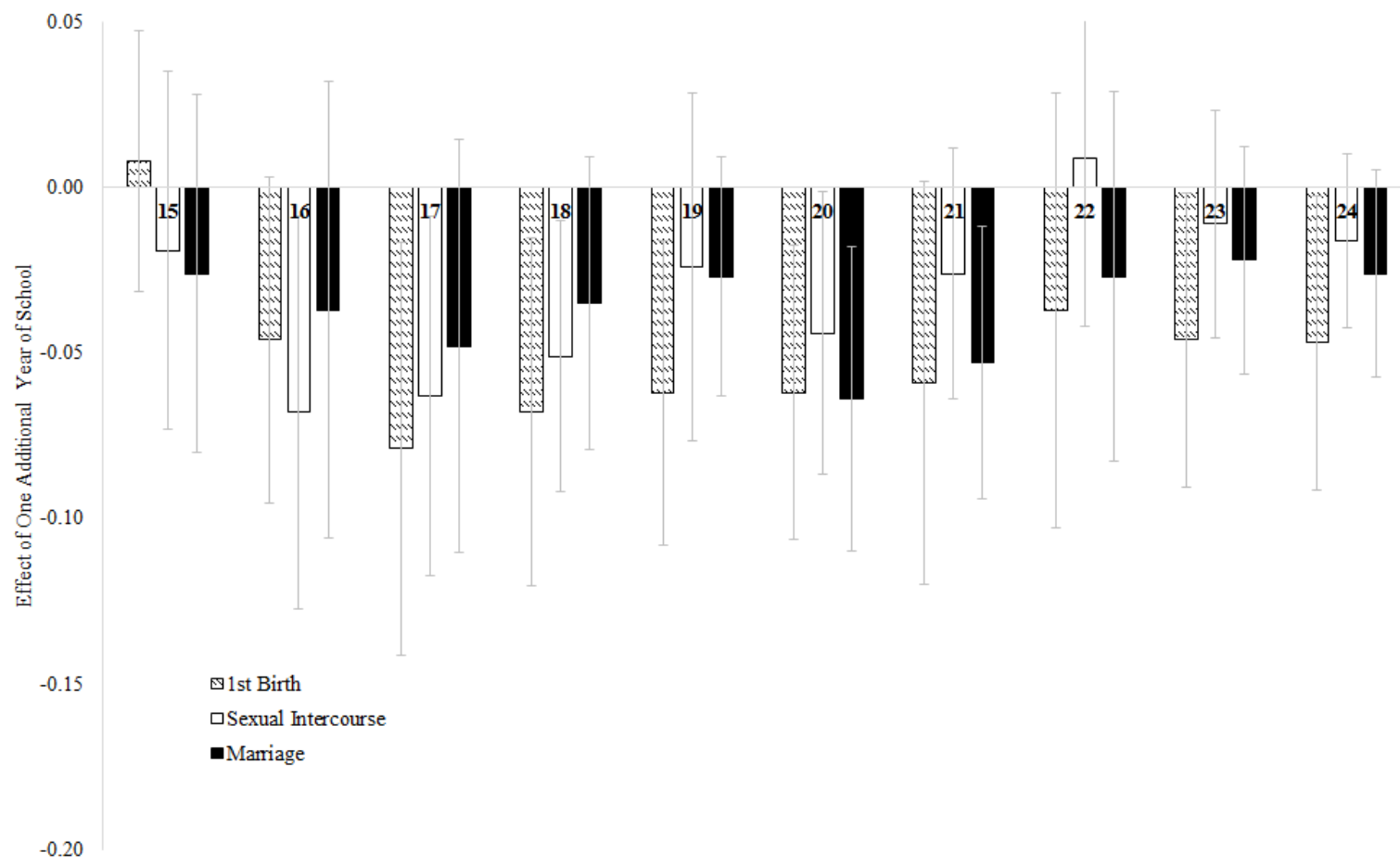

Figure 3: Effect of Years of Schooling on Age at First Birth, Sexual Intercourse, and Marriage (90\% C.I)

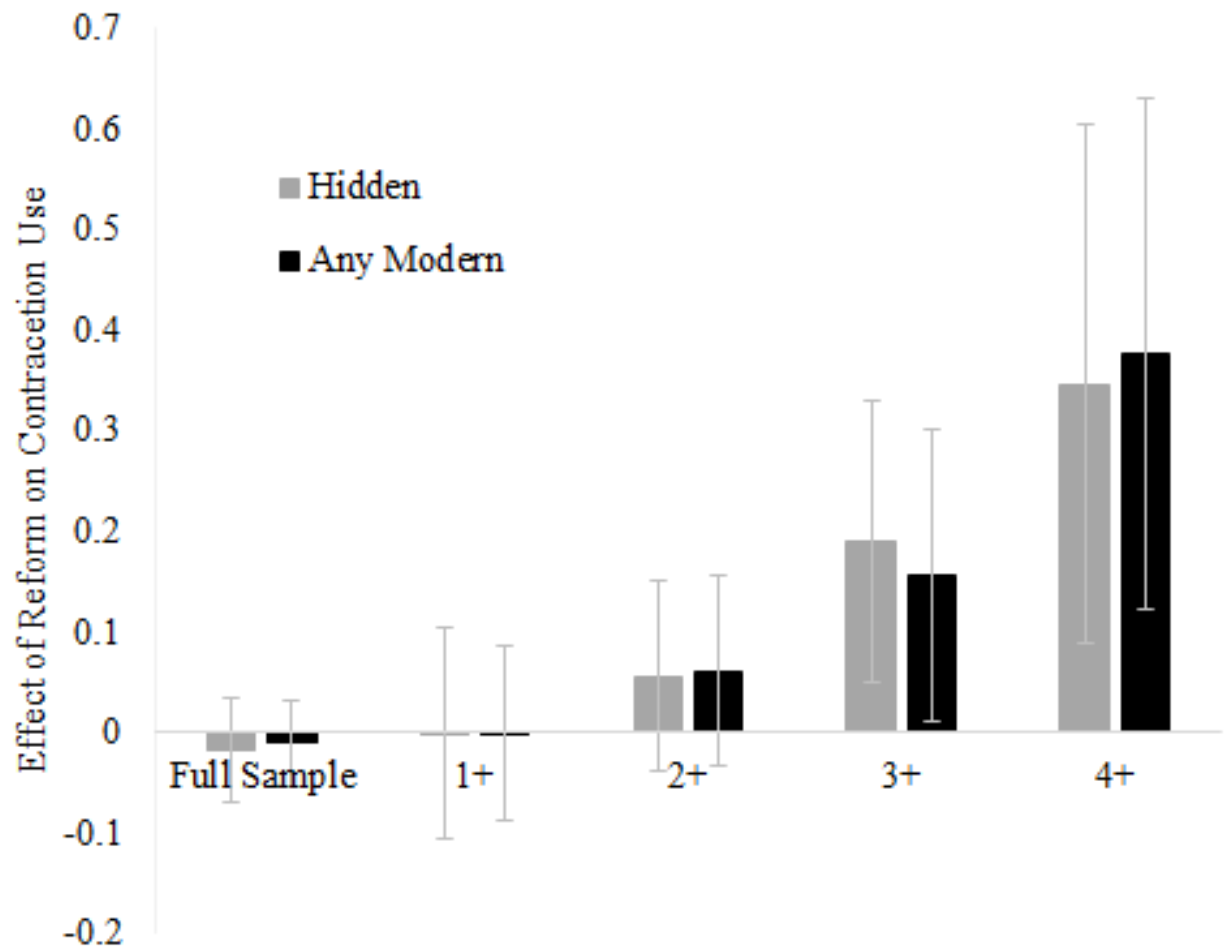

Figure 4: Effect of Years of Schooling on Use of Contraception, by Family Size (90\% C.I) 


\section{Tables}

Table 1: Summary Statistics

\begin{tabular}{|c|c|c|c|c|c|c|c|c|c|}
\hline \multirow[t]{2}{*}{ Birth Cohorts: } & \multicolumn{2}{|c|}{1966 to 1970} & \multicolumn{2}{|c|}{1986 to 1990} & & \multicolumn{2}{|c|}{1966 to 1970} & \multicolumn{2}{|c|}{1986 to 1990} \\
\hline & $N$ & Mean & $N$ & Mean & & $N$ & Mean & $N$ & Mean \\
\hline Years of Schooling & 1,780 & 2.345 & 4,620 & 4.615 & First Birth & & & & \\
\hline $\begin{array}{l}\text { Number of Births } \\
\text { Ideal Number of Children } \\
\text { Number of Births }\end{array}$ & $\begin{array}{l}1,780 \\
1,550\end{array}$ & $\begin{array}{l}5.375 \\
6.045\end{array}$ & $\begin{array}{l}4,620 \\
4,367\end{array}$ & $\begin{array}{l}0.507 \\
3.870\end{array}$ & $\begin{array}{r}\text { Age } 15 \\
17 \\
20 \\
22\end{array}$ & $\begin{array}{l}1,780 \\
1,780 \\
1,780 \\
1,780\end{array}$ & $\begin{array}{l}0.190 \\
0.375 \\
0.641 \\
0.770\end{array}$ & $\begin{array}{c}4,023 \\
3,014 \\
1,613 \\
868\end{array}$ & $\begin{array}{l}0.063 \\
0.191 \\
0.427 \\
0.565\end{array}$ \\
\hline $\begin{array}{r}\text { Age } 15 \\
17 \\
20\end{array}$ & $\begin{array}{l}1,780 \\
1,780 \\
1,780\end{array}$ & $\begin{array}{l}0.229 \\
0.548 \\
1.226\end{array}$ & $\begin{array}{l}4,023 \\
3,014 \\
1,613\end{array}$ & $\begin{array}{l}0.073 \\
0.235 \\
0.660\end{array}$ & $\begin{array}{r}24^{*} \\
\text { Second Birth }\end{array}$ & 1,780 & 0.831 & 116 & 0.771 \\
\hline $\begin{array}{r}22 \\
24^{*} \\
\text { First Sexual Intercourse }\end{array}$ & $\begin{array}{l}1,780 \\
1,780\end{array}$ & $\begin{array}{l}1.772 \\
2.334\end{array}$ & $\begin{array}{l}868 \\
751\end{array}$ & $\begin{array}{l}1.051 \\
1.826\end{array}$ & $\begin{array}{r}\text { Age } 15 \\
17 \\
20 \\
22\end{array}$ & $\begin{array}{l}1,780 \\
1,780 \\
1,780 \\
1,780\end{array}$ & $\begin{array}{l}0.035 \\
0.143 \\
0.365 \\
0.537\end{array}$ & $\begin{array}{c}4,023 \\
3,014 \\
1,613 \\
868\end{array}$ & $\begin{array}{l}0.008 \\
0.040 \\
0.170 \\
0.302\end{array}$ \\
\hline $\begin{array}{r}\text { Age } 15 \\
17 \\
20\end{array}$ & $\begin{array}{l}1,780 \\
1,780 \\
1,780\end{array}$ & $\begin{array}{l}0.450 \\
0.633 \\
0.837\end{array}$ & $\begin{array}{l}4,023 \\
3,014 \\
1,613\end{array}$ & $\begin{array}{l}0.196 \\
0.383 \\
0.638\end{array}$ & $\begin{array}{r}24^{*} \\
\text { Third Birth }\end{array}$ & 1,780 & 0.665 & 751 & 0.547 \\
\hline $\begin{array}{r}22 \\
24^{*} \\
\text { First Marriage }\end{array}$ & $\begin{array}{l}1,780 \\
1,780\end{array}$ & $\begin{array}{l}0.889 \\
0.919\end{array}$ & $\begin{array}{l}868 \\
751\end{array}$ & $\begin{array}{l}0.759 \\
0.885\end{array}$ & $\begin{array}{r}\text { Age } 15 \\
17 \\
20 \\
22\end{array}$ & $\begin{array}{l}1,780 \\
1,780 \\
1,780 \\
1,780\end{array}$ & $\begin{array}{l}0.003 \\
0.025 \\
0.154 \\
0.293\end{array}$ & $\begin{array}{c}4,023 \\
3,014 \\
1,613 \\
868\end{array}$ & $\begin{array}{l}0.001 \\
0.008 \\
0.053 \\
0.135\end{array}$ \\
\hline $\begin{array}{r}\text { Age } 15 \\
17 \\
20 \\
22 \\
24^{*}\end{array}$ & $\begin{array}{l}1,780 \\
1,780 \\
1,780 \\
1,780 \\
1,780\end{array}$ & $\begin{array}{l}0.441 \\
0.613 \\
0.803 \\
0.858 \\
0.893\end{array}$ & $\begin{array}{c}4,023 \\
3,014 \\
1,613 \\
868 \\
751\end{array}$ & $\begin{array}{l}0.192 \\
0.360 \\
0.567 \\
0.687 \\
0.840\end{array}$ & $\begin{array}{r}\text { Working } \\
\text { Earning Cash } \\
\text { Non-Subsistance Ag. } \\
\text { Non-Agriculture }\end{array}$ & $\begin{array}{l}1,780 \\
1,780 \\
1,770 \\
1,770\end{array}$ & $\begin{array}{l}0.358 \\
0.294 \\
0.336 \\
0.278\end{array}$ & $\begin{array}{l}4,616 \\
4,620 \\
4,600 \\
4,600\end{array}$ & $\begin{array}{l}0.288 \\
0.251 \\
0.307 \\
0.255\end{array}$ \\
\hline \multicolumn{10}{|l|}{ Difference with Husband } \\
\hline $\begin{array}{r}\text { Age } \\
\text { Education }\end{array}$ & $\begin{array}{l}1,420 \\
1,711\end{array}$ & $\begin{array}{l}-9.398 \\
-0.997\end{array}$ & $\begin{array}{l}1,699 \\
1,937\end{array}$ & $\begin{array}{l}-7.685 \\
-1.041\end{array}$ & $\begin{array}{l}\text { No Justification } \\
\text { for Beating Wife }\end{array}$ & 1,715 & 0.282 & 4,334 & 0.365 \\
\hline
\end{tabular}

Note: *Age 24 means are calculated using both 1985 and 1986 cohorts to include two cohorts with observations above the age of 24. Data are for women in the 2005 and 2011 rounds of the Ethiopian DHS. Difference with husband values are calculated as wife's value minus husband's value; a negative number denotes the a higher value associated with the husband. 


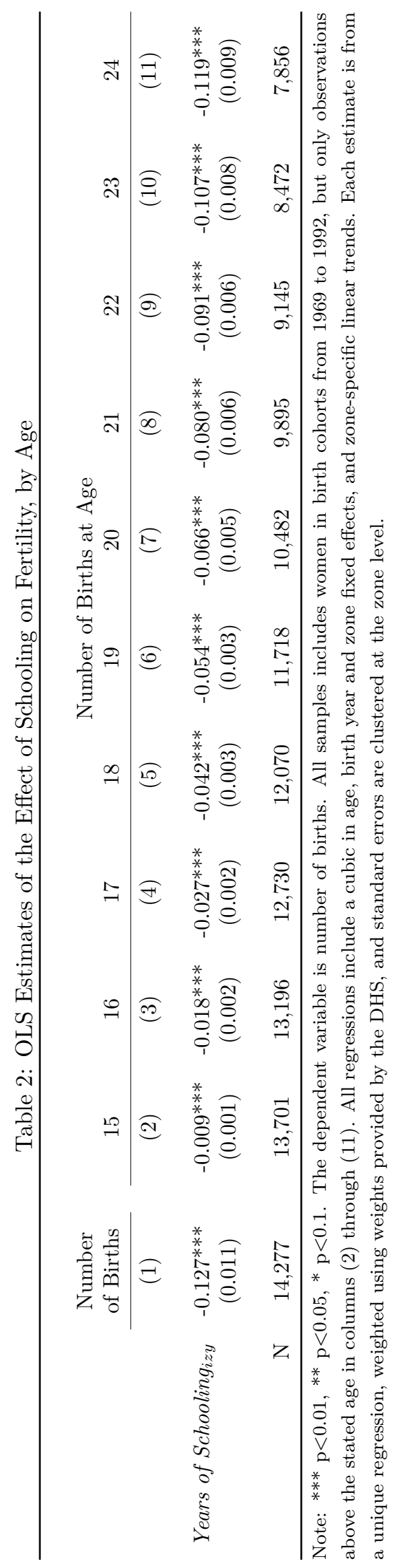


Table 3: First Stage - Effect of Reform on Years of Schooling

\begin{tabular}{|c|c|c|c|c|c|c|c|}
\hline & \multirow{2}{*}{$\begin{array}{c}\text { Baseline } \\
(1970-1990) \\
\end{array}$} & \multirow{2}{*}{$\begin{array}{c}\text { Uniform } \\
\text { Implementation }\end{array}$} & \multirow{2}{*}{$\begin{array}{c}\text { Regional } \\
\text { Trends }\end{array}$} & \multicolumn{4}{|c|}{ Alternative Samples } \\
\hline & & & & (1969 to 1991) & (1968 to 1992$)$ & (1967 to 1993$)$ & (1966 to 1994$)$ \\
\hline & (1) & (2) & (3) & (4) & (5) & (6) & (7) \\
\hline Reform Intensity $z y$ & $\begin{array}{c}1.732^{* * * *} \\
(0.375)\end{array}$ & $\begin{array}{c}1.268^{* * * *} \\
(0.332)\end{array}$ & $\begin{array}{c}1.838^{* * *} \\
(0.412)\end{array}$ & $\begin{array}{c}1.746^{* * * *} \\
(0.400)\end{array}$ & $\begin{array}{c}1.659^{* * *} \\
(0.382)\end{array}$ & $\begin{array}{c}1.650^{* * *} \\
(0.389)\end{array}$ & $\begin{array}{c}1.699^{* * * *} \\
(0.384)\end{array}$ \\
\hline F-Statistic & 21.32 & 14.55 & 19.92 & 19.05 & 18.82 & 18.02 & 19.60 \\
\hline$N$ & 14,277 & 14,277 & 14,277 & 15,095 & 15,832 & 16,569 & 17,316 \\
\hline
\end{tabular}

Note: ${ }^{* * *} \mathrm{p}<0.01,{ }^{* *} \mathrm{p}<0.05,{ }^{*} \mathrm{p}<0.1$. The dependent variable is years of schooling. Reform Intensity $z y$ is the estimated intensity of the education reform in zone $z$, for women born in year $y$. Samples in columns (1) to (3) include women in birth cohorts from 1970 to 1990; columns (4) to (7) expand the range of birth cohorts included. In column (2), the Reform Intensityzy is calculated by assuming uniform implementation of the reform within each region. All regressions include a cubic in age, birth year and zone fixed effects. Zone-specific linear trends are also included in all regressions expect column (3), which is estimated using region-specific trends. Each estimate is from a unique regression, weighted using weights provided by the DHS, and standard errors are clustered at the zone level.

Table 4: 2SLS - Effect of Years of Schooling on Fertility

\begin{tabular}{|c|c|c|c|c|c|c|c|}
\hline & \multirow{2}{*}{$\begin{array}{c}\text { Baseline } \\
(1970-1990)\end{array}$} & \multirow{2}{*}{$\begin{array}{c}\text { Uniform } \\
\text { Implementation }\end{array}$} & \multirow{2}{*}{$\begin{array}{c}\text { Regional } \\
\text { Trends }\end{array}$} & \multicolumn{4}{|c|}{ Alternative Samples } \\
\hline & & & & (1969 to 1991$)$ & (1968 to 1992$)$ & (1967 to 1993 ) & (1966 to 1994$)$ \\
\hline & (1) & $(2)$ & (3) & (4) & (5) & (6) & (7) \\
\hline Years of Schooling ${ }_{i z y}$ & $\begin{array}{c}-0.164^{* *} \\
(0.074)\end{array}$ & $\begin{array}{c}-0.161^{*} \\
(0.085)\end{array}$ & $\begin{array}{c}-0.175^{* *} \\
(0.071)\end{array}$ & $\begin{array}{c}-0.191^{* *} \\
(0.077)\end{array}$ & $\begin{array}{c}-0.209^{* *} \\
(0.086)\end{array}$ & $\begin{array}{c}-0.192^{* *} \\
(0.080)\end{array}$ & $\begin{array}{c}-0.177^{* *} \\
(0.074)\end{array}$ \\
\hline First Stage F-Statistic & 21.32 & 14.55 & 19.92 & 19.05 & 18.82 & 18.02 & 19.60 \\
\hline$N$ & 14,277 & 14,277 & 14,277 & 15,095 & 15,832 & 16,569 & 17,316 \\
\hline
\end{tabular}

Note: ${ }^{* *} \mathrm{p}<0.01,{ }^{*} \mathrm{p}<0.05,{ }^{*} \mathrm{p}<0.1$. The dependent variable is number of births. Years of Schooling ${ }_{i z y}$ is the predicted level of schooling, instrumented with the reform intensity measure, $I_{z y}$. Samples in columns (1) to (3) include women in birth cohorts from 1970 to 1990; columns (4) to (7) expand the range of birth cohorts included. In column (2), the Reform Intensity $z y$ used to predict years of schooling is calculated by assuming uniform implementation of the reform within each region. All regressions include a cubic in age, birth year and zone fixed effects. Zone-specific linear trends are also included in all regressions expect column (3), which is estimated using region-specific trends. Each estimate is from a unique regression, weighted using weights provided by the DHS, and standard errors are clustered at the zone level. 


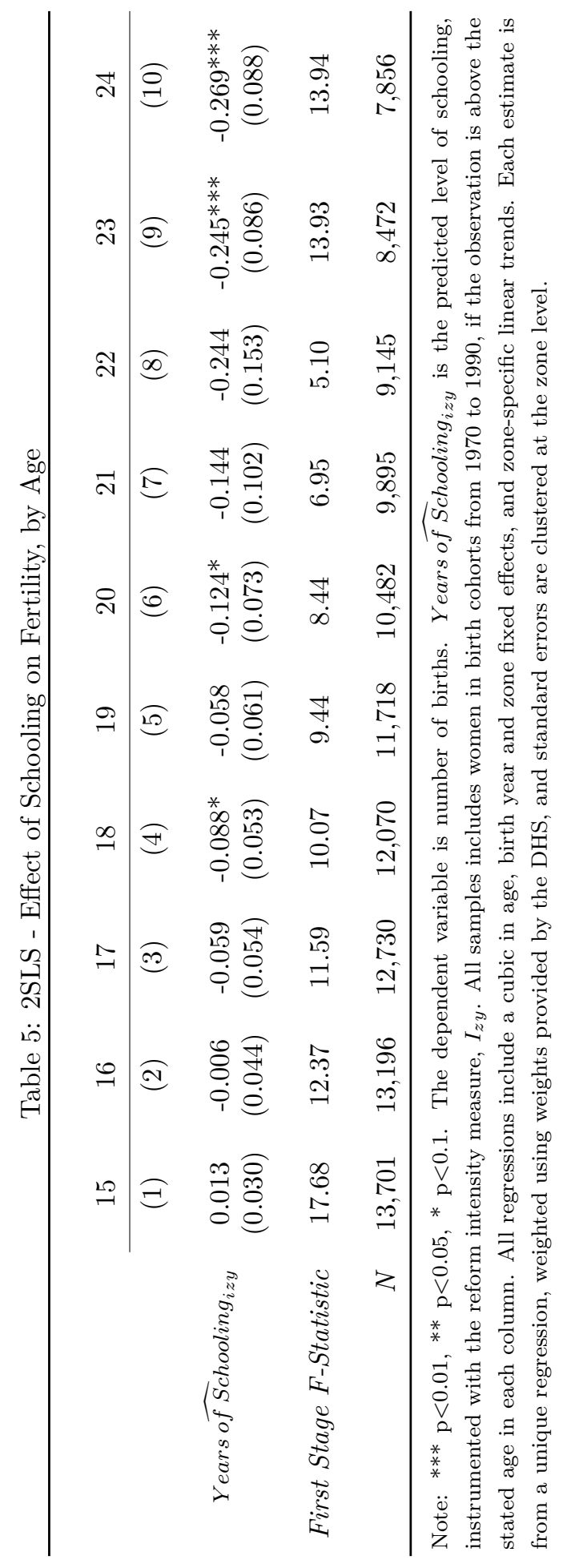




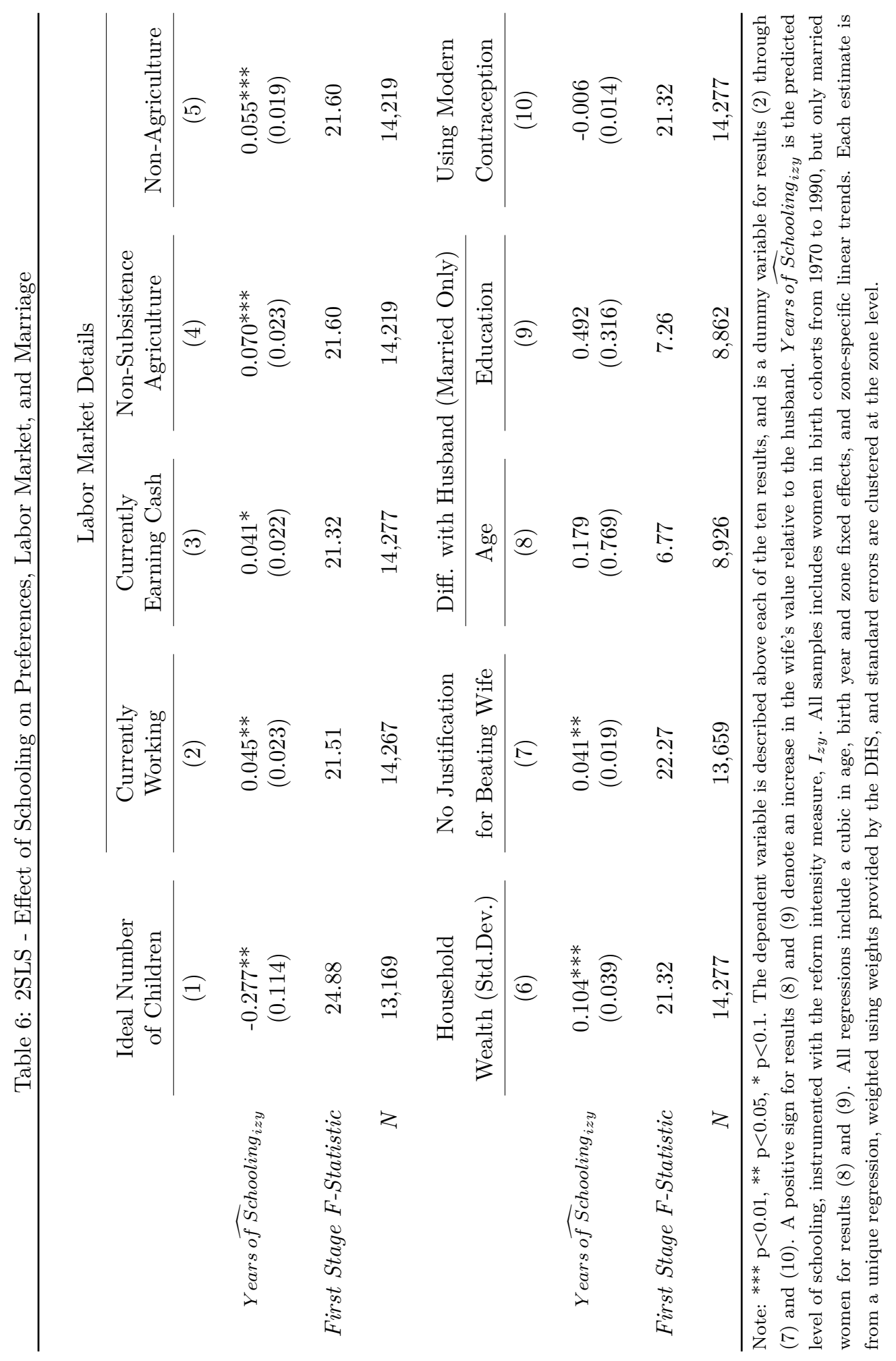




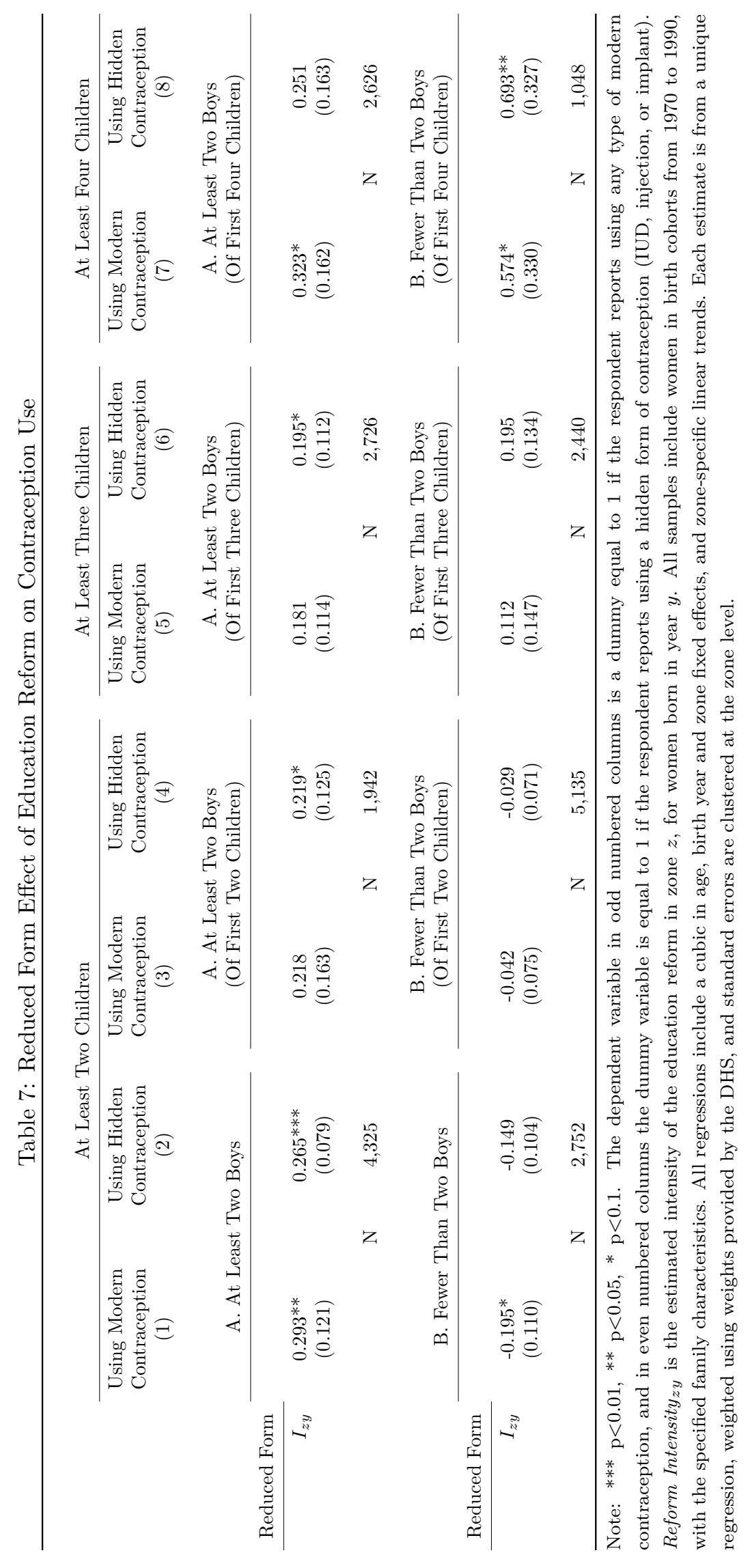




\section{A Online Appendix}

Table A1: Effect of Schooling on Timing of Birth, Sex, and Marriage - Estimates from Figures 2 and 3

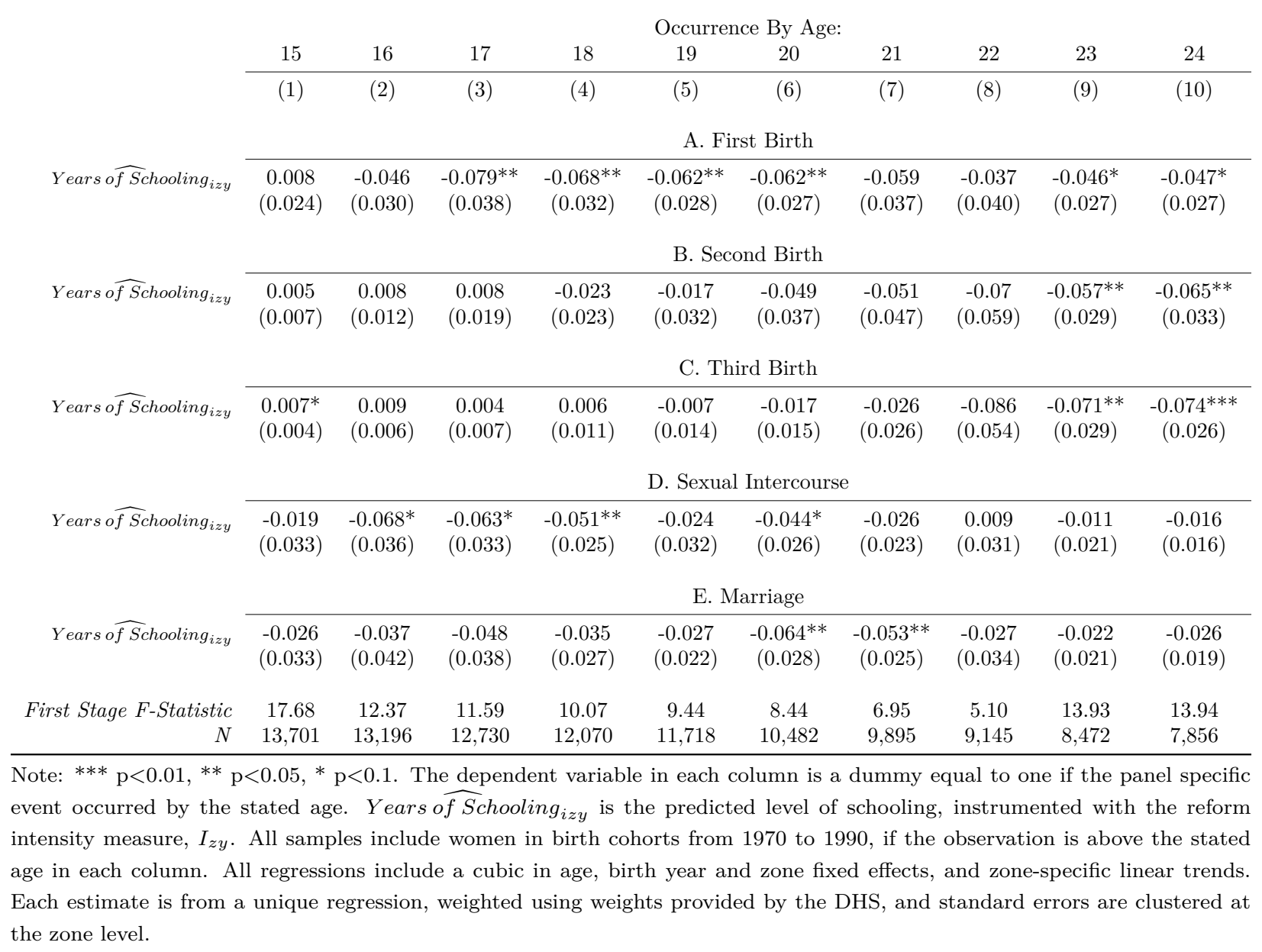


Table A2: 2SLS - Effect of Years of Schooling on Women Having Say in Household Decisions

\begin{tabular}{|c|c|c|c|c|c|}
\hline \multirow[b]{3}{*}{ Reform Intensity $_{z y}$} & $\begin{array}{c}\text { Years of } \\
\text { Schooling }\end{array}$ & & $\begin{array}{c}\text { Personal } \\
\text { Healthcare }\end{array}$ & $\begin{array}{l}\text { Have a Say In: } \\
\text { Large Household } \\
\text { Purchases }\end{array}$ & $\begin{array}{l}\text { Visiting } \\
\text { Relatives }\end{array}$ \\
\hline & (1) & & $(2)$ & (3) & (4) \\
\hline & $\begin{array}{c}1.332^{* *} \\
(0.504)\end{array}$ & Years of $\widehat{f}$ chooling ${ }_{i z y}$ & $\begin{array}{c}0.021 \\
(0.040)\end{array}$ & $\begin{array}{l}-0.011 \\
(0.053)\end{array}$ & $\begin{array}{l}-0.030 \\
(0.054)\end{array}$ \\
\hline F-Statistic & 6.97 & & 6.97 & 6.97 & 6.97 \\
\hline$N$ & 8,899 & & 8,899 & 8,899 & 8,899 \\
\hline
\end{tabular}




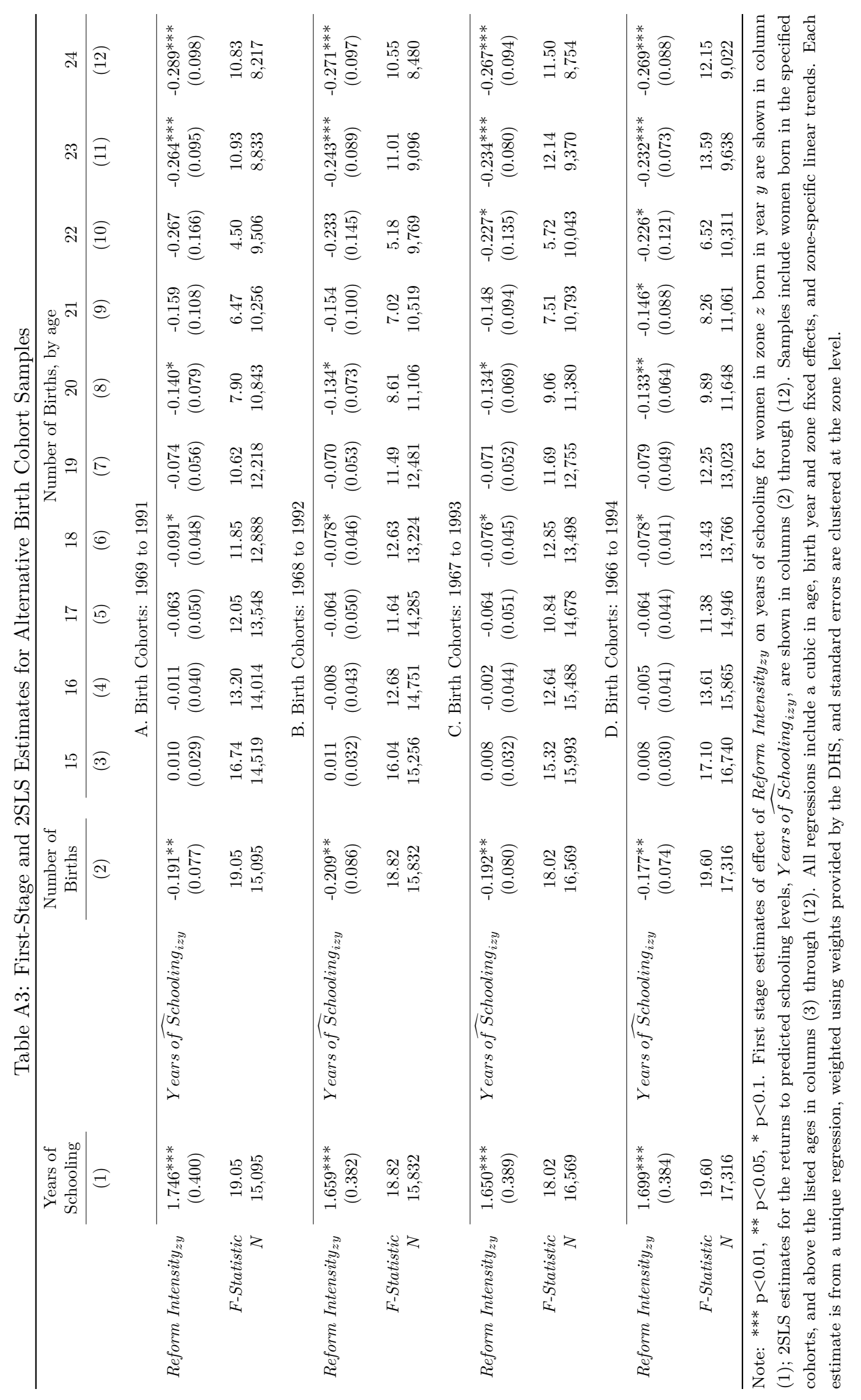




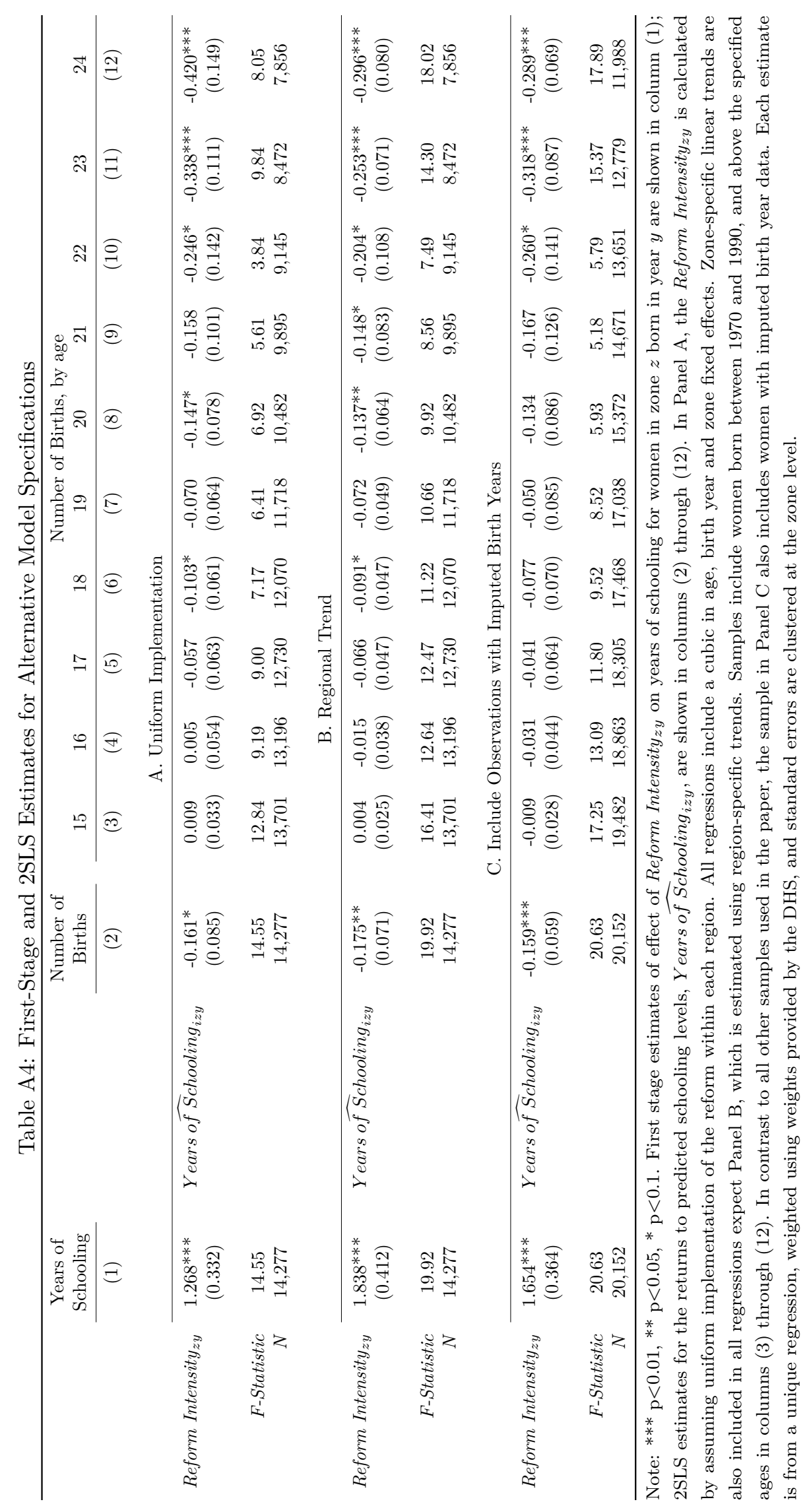

